\title{
WHAT DOES THAT LUGWERE DEMONSTRATIVE REFER TO? A SEMANTIC ANALYSIS OF PROXIMITY AND EXTERIORITY
}

\author{
Dorothy Ahn \& Jenneke van der Wal \\ Harvard University \& Leiden University Centre for Linguistics
}

\begin{abstract}
The Bantu language Lugwere (Uganda, JE17) has what at first sight appears to be a typical three-way distinction in its demonstratives, with a proximal, medial, and distal series of demonstratives. Upon closer inspection, however, the second series in Lugwere can also be used for distal and anaphoric referents, whereas the third series has a more restricted use. We propose a better fitting semantic analysis in terms of the features $[ \pm$ proximal] and [ \pm exterior], the latter referring to the status of a referent being inside or outside a certain perimeter, which is set by either the spatial environment of the conversation or the constantly updated discourse ground. This captures the semantic distinctions in the three series of demonstratives in Lugwere and provides an insight into the building blocks of demonstrative meaning.
\end{abstract}

Keywords: anaphoricity, demonstratives, semantics, Bantu, Lugwere

\section{Introduction}

Lugwere is a Bantu language classified as JE17 in Maho's (2009) updated version of Guthrie's classification. It is spoken in the Pallisa district of Uganda by around 621,000 people (2014 census, via Ethnologue, Simons \& Fennig 2017). As is typical for a Bantu language, Lugwere nouns are divided into noun classes, numbered in the glosses. This is visible in the shape of the noun, consisting of a noun stem preceded by a noun class prefix and an augment, as well as the concord in the phrase (1) and agreement in the clause (2).

a.

$$
\begin{array}{ll}
\text { é-cí-tóóké } & \text { é-ci-nené1 } \\
\text { AUG-7-plantain } & \text { AUG-7-big } \\
\text { 'a/the big plantain' } &
\end{array}
$$

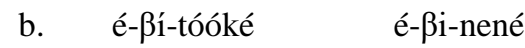
AUG-8-plantain AUG-8-big
'big plantains'

(2)
a. Ó-mu-timá gu-kúba.
'The heart beats.'
b. É-mi-timá ji-kúba.

'Hearts beat.'

\footnotetext{
${ }^{1}$ The data in this paper come from the authors' elicitation work with Andrew Nalani in spring 2017, unless otherwise indicated. We are very grateful to Andrew for sharing his insights in Lugwere, and to the Harvard Ling $117 \mathrm{r}$ class for sharing materials and data with us. We furthermore thank Mark Van de Velde and Steve Nicolle for their comments. The usual disclaimers apply.
} 
The current paper is concerned with demonstratives in Lugwere, which equally show concord in noun class with the noun they modify:

$\begin{array}{lll}\text { á-ká-sólo ka-nó } & \text { á-ká-ZW-iíré } \\ \text { AUG-12-animal } & \text { 12-DEM.I } & \text { 12REL-12SM-come.out-PFV } \\ \text { 'This small animal which has come out of the hole...' }\end{array}$

ó-mú-ci-tuli...

AUG-18-7-hole

'This small animal which has come out of the hole...'

The demonstratives exist in three series, all showing concord for noun class, as illustrated in Table 1.

\begin{tabular}{|c|c|c|c|c|}
\hline noun class & AUG+NPx & DEM I & DEM II & DEM III \\
\hline 1 & o-mu/o-mw & o-no & oy-o & o-di \\
\hline 2 & $\mathrm{a}-\beta \mathrm{a}$ & $\beta a-n o$ & $\mathrm{a} \beta-\mathrm{o}$ & $\beta a-d i$ \\
\hline 3 & o-mu/o-mw & gu-no & ogw-o & gu- \\
\hline 4 & e-mi/e-my & ji-no & eej-o & ji-di \\
\hline 5 & e-ri/e-i & li-no & ery-o & li-di \\
\hline 6 & a-ma & ga-no & ag-o & ga-di \\
\hline 7 & e-ci & ci-no & ec-o & ci-di \\
\hline 8 & $e-\beta i$ & $\beta \mathrm{i}-$ no & e $\beta y-o$ & $\beta \mathrm{i}$-di \\
\hline 9 & e-N & e-no & ey-o & e-di \\
\hline 10 & e-N & ji-no & ej-o & ji-di \\
\hline 11 & o-lu & lu-no & olw-o & lu-di \\
\hline 12 & a-ka & ka-no & ak-o & ka-di \\
\hline 13 & $o-\beta u$ & $\beta u-n o$ & $\mathrm{o} \beta \mathrm{w}-\mathrm{O}$ & $\beta u$-di \\
\hline 15 & o-ku & ku-no & okw-o & ku-di \\
\hline 16 & a-wa & wa-no & aw-o & wa-di \\
\hline 17 & o-ku & ku-no & okw-o & ku-di \\
\hline 18 & o-mu & mu-no & omw-o & mu-di \\
\hline 20 & o-gu & gu-no & ogw-o & gu-di \\
\hline 22 & a-ga & ga-no & ag-o & ga-di \\
\hline
\end{tabular}

Table 1. Three demonstrative series in Lugwere

While a three-way distinction for demonstratives is very common in Bantu languages (Weier 1985), the Lugwere series cannot be captured in a simple distinction near-speaker vs. near-hearer vs. further away from both, as is usual for these three series of demonstratives in other languages (though see Meira \& Terrill 2005 for discussion of how the usual three-way distinction might not reflect underlying differences between languages). The first indication that the system of demonstratives works differently in Lugwere is the fact that in elicitation the third series did not spontaneously come up, even when asked about reference to an object far away. Instead, the second series was used for anything that was not in the direct proximity of the speaker, as shown in (4).

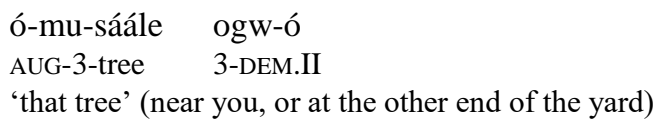

Our research questions in this paper are therefore the following: 
1. In which environments can each series of demonstratives be used?

2. What is the inherent and implied meaning of each series?

We first show the general distribution of demonstratives in Lugwere in section 2, then focus on the differences between the three series in section 3, proposing an analysis in terms of the two features [ \pm proximal] and [ \pm exterior]. We show the arguments for this proposal in detail in section 4 , and close with a discussion and conclusion in sections 5 and 6 . We also note here that the proposed analysis is necessarily limited because of the nature of the data (elicited from one speaker) and hence is intended as a hypothesis to be tested further in spontaneous language use and larger stretches of text, where further text-organizing functions may come to the fore (see e.g. Nicolle 2014, Van der Wal 2010).

\section{Distribution of demonstratives}

All three series can be used adnominally, illustrated above in (3) and (4), as well as pronominally. The forms as given in Table 1 can be used by themselves as in (5), and there is a longer form for each as well, as illustrated in (6), and indicated by /:/ in the gloss. The longer forms are described as indicating a choice between two alternatives.
a. gu-n’ ó-gu-sóóka
3-DEM.I REL-3-lead
'this first one'
b. ogw' ó-gu-sóóka
3.DEM.II REL-3-lead
'that first one'
c. gu-di ó-gu-sóóka
3-DEM.III REL-3-lead
'that first one'

(6)
1SG.SM-want 3:-DEM.I 5:-DEM.I
'I like this one (tree/tooth).'
a. N-táká gúu-no / líi-no. ${ }^{2}$
b. N-táká gúu-gw-o / líi-ry-o.
1SG.SM-want 3:-3-DEM.II 5:-5-DEM.II
'I like that one (tree/tooth).'
c. N-táká gúu-di / líi-di.
1SG.SM-want 3:-DEM.I 5:-DEM.I
'I like that one (tree/tooth).'

\footnotetext{
2 The verb okutaka can be interpreted as 'want' or 'like'. We consistently gloss it as 'want' but the free translation will reflect the most natural interpretation in each case.
} 
Adnominally, demonstratives can occur in pre- or post-nominal position, with the latter form being the default order. The pre-nominal order receives a more emphatic reading ("really this child, I'm telling you!"). See Van de Velde (2005) for a cross-Bantu overview of noun-demonstrative order.

(7) Series I
a. á-má-víívi ga-nó
AUG-6-knees 6-DEM.I
$\begin{array}{ll}\text { b. } & \text { ga-no á-mávíívi } \\ \text { 6-DEM.I } \\ \text { 'these knees' }\end{array}$

(8) Series II
a. ó-mw-aan' óo-yo
AUG-1-child 1-DEM.II
b. oy’ ó-mw-aaná
1.DEM.II AUG-1-child
'that child'

(9) Series III
a. ó-mu-kali o-dí
AUG-1-woman 1-DEM.III
b. o-di ó-mu-kalí
1-DEM.III AUG-1-woman
'that woman'

We leave aside the emphatic dem-N order and focus on the $\mathrm{N}$-dem order in this paper.

\section{Analysis of three series varying according to [ \pm proximal] and [ \pm exterior]}

Before we provide detailed information on the distribution and interpretation of each of the demonstrative series (see section 4), we first informally characterize their use in section 3.1 and explain in section 3.2 our proposal to account for the semantic properties by two features [ \pm proximal] and [ $[$ exterior $]$.

3.1. Basic description of the meaning of each series. Cross-linguistically, lexical elements that fall under the loose term "demonstratives" are used to identify referents in the physical context (exophoric reference, often accompanied by a pointing gesture) as well as referents in the previous discourse (endophoric reference). Bantu demonstrative systems frequently distinguish three demonstrative series differing in exophoric deixis according to distance from the speaker, as deictic center: proximal, medial and distal. ${ }^{3}$

In Lugwere, demonstratives in series I are used exophorically for proximal referents only. Series I can also be used endophorically but this is unusual. Series II is used both exophorically and endophorically. Exophorically it refers to non-proximal referents, and endophorically, it can refer

\footnotetext{
${ }^{3}$ Systems distinguishing 4 series are also frequent (Nicolle 2012, Weier 1985).
} 
to both discourse-accessible referents and be bound like a variable (see Schwarz 2009 for tests of familiarity that we adopt in the current paper). Unlike in many other Bantu languages, series III in Lugwere does not refer exophorically unless a boundary can be identified potentially establishing a contrast. Endophorically, series III can refer to an already established but currently inactive referent, but it cannot be bound like a variable.

3.2. Semantics and features [ \pm proximal] and [ \pm exterior]. In order to capture the meaning of the three series of demonstratives in Lugwere, we propose the following analysis. The basic semantic description of the three series takes the following form:

(10) $\llbracket N O U N \operatorname{dem} \rrbracket=1 x[\operatorname{NOUN}(x) \& x=y]$

a. $\quad \mathrm{y}$ is an index which could be bound by an operator, covarying with another linguistic element, or indicated by pointing in exophoric contexts.

Thus, a noun followed by a demonstrative returns a unique $\mathrm{x}$ such that $\mathrm{x}$ satisfies the description NOUN and $x$ corefers with $y$. In addition to the basic semantics that applies to all three series of demonstratives, we also propose two features by which the three series can be distinguished in (11), where by the term perimeter we mean the physical and discourse context shared by the speaker and the addressee (see below).

(11) a. [+proximal]: The referent is proximal to the speaker

[-proximal]: The referent is not proximal to the speaker

b. [+exterior]: The referent is placed outside the speech perimeter

[-exterior]: The referent is placed inside the speech perimeter

The [ \pm proximal] feature is not new. English demonstratives this and that can be said to differ in these two aspects in exophoric uses, where this is [+proximal] and that is [-proximal]. The [ \pm exterior] feature is a novel feature that we introduce for Lugwere, inspired by Burenhult's (2008) discussion of Jahai demonstratives. In discussing the distribution of demonstratives in Jahai, Burenhult lists three parameters: access, exterior, and elevation. As soon as a speaker addresses another person, the area between the two participants become a spatial entity, the boundaries of which are called a 'perimeter'. Referents outside of this perimeter are referred to by an exterior demonstrative in Jahai.

We adopt the notion of an exterior demonstrative and define it to be referring to entities outside a perimeter, but we modify the notion of a 'perimeter' in two main aspects to account for the Lugwere data. First, we extend the notion of the perimeter to include not only spatial contexts but also discourse contexts. A concept of a discourse perimeter may be equated to a discourse representation structure or a set of discourse referents in Discourse Representation Theory (DRT; cf. Kamp 1981; Heim 1982, 1983, a.o.). Second, we change the static perimeter in Burenhult's study into something that can be dynamically updated as the discourse proceeds, just like the representation structure and the set of discourse referents are updated as the conversation proceeds. The exact way in which our extension of Burenhult's perimeter is similar to and different from the set of discourse referents in DRT is left for future investigation. We use the following definition of a perimeter: 
perimeter: boundary of the physical and/or discourse context initially defined by the (physical and discourse) space shared by the speaker and the hearer, and updated as the discourse proceeds to include the introduced referents.

The notion of a perimeter in the discourse domain is related to what Himmelmann (1996) calls the 'recognitional use' of demonstratives. According to Himmelmann, a demonstrative can be used by a speaker to refer to something that is not immediately familiar from current discourse. Himmelmann presents a demonstrative found in Mparntwe Arrernte, spoken in Alice Springs in Central Australia, as an example of this use. This demonstrative is described in Wilkins 1989 as a 'remember' demonstrative, referring to something from previous discourse that the addressee may remember.

With this new notion of perimeter, we illustrate how a perimeter would be updated as a conversation proceeds, and what it would mean to be [+exterior] or [-exterior] with respect to the updated perimeter.

When the conversation in (13) starts, the perimeter simply contains the speaker and the addressee as shown in (13a). Once the speaker notices a cat nearby and talks about its eyes, the perimeter is updated to include the cat, as shown in (13b). In (13c), the speaker talks about a mutual friend that both of the conversation participants know. Note that up until (13c), the mutual friend, while familiar to both, is [+exterior] because she is not part of the conversation in (13b). Once the friend is mentioned, the perimeter is updated to include the friend, as in (13c).

(13) Discourse context

\begin{tabular}{|l|l|l|}
\hline conversation & perimeter & [+exterior $]$ \\
\hline a. Beginning of the conversation & [speaker, addressee $]$ & $\begin{array}{l}{[\text { cat], [mutual }} \\
\text { friend]... }\end{array}$ \\
\hline $\begin{array}{l}\text { b. Speaker and addressee notice a cat } \\
\text { nearby and talk about its eyes }\end{array}$ & [speaker, addressee, cat] & [mutual friend]... \\
\hline $\begin{array}{l}\text { c. Speaker and addressee talk about a } \\
\text { mutual friend }\end{array}$ & $\begin{array}{l}\text { [speaker, addressee, cat, } \\
\text { mutual friend] }\end{array}$ & $\ldots$ \\
\hline
\end{tabular}

We propose that the three series of demonstratives in Lugwere have the feature specifications in (14), where $y$ refers to the index in (10):

(14) I: the referent of y is [+proximal] [-exterior]

II: the referent of $y$ is [-proximal] [-exterior]

III: the referent of $y$ is [-proximal] [+exterior]

This is represented graphically in (15), where the circle represents the perimeter, and the triangles the object referred to with a demonstrative: 
(15)

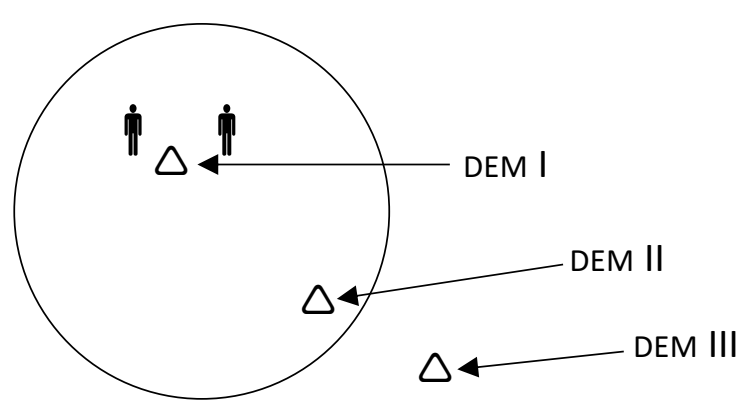

Series I is thus used to refer to proximal entities that are inside the perimeter and close to the speaker (e.g. a pear in her hand). Series II would be used to refer to a distal referent inside the perimeter or a referent inside the currently relevant perimeter in the discourse context (e.g. the cat in (13b) or the friend in (13c)). Series III on the other hand, would be used to refer to an entity that is outside the perimeter, like an entity outside the visible perimeter in a spatial context, or an entity that is not yet or no longer relevant in the current discussion in the discourse context (e.g. the friend in (13b)). The notion of [-exterior] is thus similar to the notion of familiarity discussed in the literature looking at definite descriptions (Heim 1982, Roberts 2002, a.o.). Previous utterance brings a referent into the perimeter (similar to strong familiarity in Roberts 2002), but being spatially close is also sufficient to be [-exterior] in this account.

\section{How $[ \pm$ proximal] and $[ \pm$ exterior] capture the occurrence of demonstratives}

We have proposed an analysis of demonstratives in Lugwere as in Table 2, whereby the three series are distinguished according to two features. Making use of two features, our analysis captures the presence of the three kinds of demonstratives, excluding the fourth combination of [+proximal] and [+exterior]. This is because the notion of proximity requires the referent to be close to the speaker, which rules out the possibility that it is located outside the speech perimeter: even in the initial state of conversation, the perimeter must contain the space of the speaker and the addressee.

\begin{tabular}{|l|l|l|}
\hline & {$[+$ exterior $]$} & {$[$-exterior $]$} \\
\hline [+proximal $]$ & $($ logically impossible $)$ & I \\
\hline [-proximal $]$ & III & II \\
\hline
\end{tabular}

Table 2. Feature specification of Lugwere demonstratives

We now discuss the data motivating our proposal for each demonstrative series in turn, showing their spatial, anaphoric, and discourse-deictic use.

4.1. Series I. We propose that series I is [+proximal] and [-exterior], resulting in the following denotation:

$$
\llbracket N O U N \operatorname{dem} \rrbracket=x[\operatorname{NOUN}(x) \& \mathrm{x}=\mathrm{y}]
$$

a. the referent of $y$ is [+proximal] [-exterior] 
We show in this section how the combination of the basic meaning and the two features capture the distribution of series I.

4.1.1. Spatial use series I: proximal referents. The feature [-exterior] is defined as requiring the referent to be located inside the speech perimeter. This means that series I requires the referent to be proximal to the speaker and found within the perimeter at the time of utterance. This is the case for spatial referents: entities that are proximal to the speaker and thus located within the initial starting perimeter must be referred to by series I.

$\begin{array}{ll}\text { á- } \beta \text {-aaná } & \beta a-n o ́ \\ \text { AUG-2-children } \\ \text { 'these children' }\end{array}$

4.1.2. Endophoric use series $I$. The notion of a perimeter can be extended to discourse, as discussed in section 3. Being [-exterior] thus means that the antecedent of a demonstrative description using series I must be found in the currently salient discourse referents. Thus, the [-exterior] feature is suitable for endophoric uses of demonstratives. Proximal demonstratives in other languages such as English this and Japanese ko-no are found to have endophoric uses, though they often carry additional meanings such as affectiveness or emphasis (Potts \& Schwarz 2010; Davis \& Potts 2010, a.o.). Thus, from the combination of [-exterior] and [+proximal] features, we predict the series I demonstratives to be possible but with similar emphatic uses as in English and Japanese.

This is indeed what we see with anaphoric uses of series I: our consultant commented that it is possible, as in (18), but sounds redundant and formal. Further research is necessary to see if Lugwere series I demonstratives also have affective readings similar to proximal demonstratives of other languages.

\begin{tabular}{|c|c|c|c|c|}
\hline N-á-yágííri & ó-mw-aaná. & Ó-mw-aan' & óo-no & y-á-ba-ire \\
\hline $\begin{array}{l}\text { 1SG.SM-PST-meet.PFV } \\
\text { sanyúcí. }\end{array}$ & AUG-1-child. & AUG-1-child & 1-DEM.I & 1SM-PST-be-PFV \\
\hline
\end{tabular}

Additionally, series I can be bound like a variable, or used in a correlative manner referring to an independent referent, as illustrated in (19). ${ }^{4}$ Note that this is an important test for anaphoricity, where familiarity-denoting elements such as pronouns and anaphoric definite descriptions can be bound by quantifiers (see Schwarz 2009, 2013; Ahn 2017, a.o.).

$\begin{array}{lrlll}\text { Buli ó-mw-aana } & \text { gw-e } & \text { a-bwééne } & \text { y-a-tumw-iiré } & \text { n' } \\ \text { every AUG-1-child } & \text { 1-REL } & \text { 1SM-see.PFV } & \text { 1SM-PST-talk-PFV } & \text { with } \\ \text { ó-mw-aan' } & \text { óo-no. } & & \\ \text { AUG-1-child } & \text { 1-DEM.I } & & \\ \text { 'Each }[\text { child he saw]i, he talked to [this child] }]_{\text {ikk. }} & \end{array}$

4.1.3. Discourse deixis series I: only one's own words. In discourse deixis a demonstrative refers to something that has been said previously, i.e. a proposition or a question. Discourse deixis faces the same oddness with the proximity feature as in the anaphoric use, and it turns out that series I is

\footnotetext{
${ }^{4}$ The more natural way to phrase (19) would have a simple pronoun or object marker in the second clause.
} 
unavailable for discourse deixis except for one context: if the speaker has just said the antecedent proposition herself. In this context, discourse deixis with series I is possible, as it is one of the rare cases where the antecedent is actually (discourse-wise) proximal to the speaker. This is exemplified in (20) and (21), where the earlier proposition referred to must have been made by the speaker, as indicated in the context.

(20) Context: The boss has just said in a speech that we should do high-quality research. She continues:

$\begin{array}{llll}\text { Ci-no c-á } & \text { Bu-kulu } & \text { íno. } \\ \text { 7-DEM.I } \quad \text { 7-CONN } & \text { 14-importance } & \text { INT } \\ \text { 'This is very important.' } & \end{array}$

(21) Context: You have just heard the outcome of the US 2016 elections. You repeat to yourself 'He has been elected?' and then react:

Ci-no te-ci-sóßóká!

7-DEM.I NEG-7SM-able

'This is impossible!'

As we will see in sections 4.2 and 4.3 below, the proximal demonstrative cannot be used in discourse deixis referring to someone else's speech.

4.2. Series II. Series II demonstratives are analyzed as requiring [-exterior] and [-proximal] referents:

$$
\llbracket N O U N \operatorname{dem} \rrbracket=x[\operatorname{NOUN}(\mathrm{x}) \& \mathrm{x}=\mathrm{y}]
$$

a. the referent of y is [-proximal] [-exterior]

With the given denotation, we can account for the following properties. Spatially, series II demonstratives are able to refer to all referents that are not proximal to the speaker, as long as they are located inside the perimeter. Discourse-wise, we see that series II can be used in all endophoric cases and that this is the natural demonstrative series to be used in such cases. Finally, in discourse deixis, series II can refer to discourse entities that have been spoken by participants other than the speaker.

4.2.1. Spatial use series II: non-proximal referents. Series II demonstratives are used to refer to spatially non-proximal referents. While there is a three-way formal distinction in Lugwere, all nonproximal referents can be referred to with series II, thus forming a two-way spatial distinction:

(23) Context: pineapple is on the other side of the room

$\begin{array}{lc}\text { é-náánáasí } & \text { ey-ó } \\ \text { 9-pineapple } & 9 \text {-DEM.II } \\ \text { 'that pineapple (over there)' }\end{array}$

The two-way distinction is thus distance-based, not person-based (Diessel 1999, though see Meira 2003). If proximity were measured with respect to the speech act participants, we would expect series I to be used for referents near the speaker and series II for referents near the addressee, whereas in the given context of a referent further away from both (24), series III is expected to be 
used. In contrast, Lugwere uses series II here, indicating that proximity in Lugwere demonstratives is determined by distance and not person.

(24) Context: Participants talking about a tree outside the window (far from both speaker and addressee)

$\begin{array}{lll}\text { N-ták' } & \text { ó-mu-sáál’ } & \text { oogw-ó/*guno/*gudi. } \\ \text { 1sG.SM-want } & \text { AUG-3-tree } & \text { 3-DEM.II/* DEM.I/* DEM.III } \\ \text { 'I like that tree, } & & \end{array}$

Series II demonstratives can be accompanied by a pointing gesture, and can be used to a identify a specific referent out of many other potential referents as in (25), or refer to different referents in one sentence as in (26) when accompanied by pointing.

$\begin{array}{lll}\text { N-ták' } & \text { é-nyuumb' } & \text { ée-yo. } \\ \text { 1sG.SM-want } & \text { 9-house } & \text { 9-DEM.II } \\ \text { 'I like that house.' } & & \end{array}$

(26) É-nyuumb' éé-yo n-nené; é-nyuumb’ éé-yo n-tóno. 9-house 9-DEM.II 9-big; 9-house 9-DEM.II 9-small

'That house is big, that house is small.' (pointing at each)

It can also be used in a context where there is no joint attention between the speaker and the adressee. In other words, the speaker can use a series II demonstrative to point out a referent that is spatially accessible but currently not active in the addressee's mind. This is shown in (27).

$\begin{array}{lll}\text { Ó-ßon' } & \text { Ó-mu-sáál' } & \text { óógw-o! } \\ \text { 2sG.SM-see.OPT } & \text { AUG-3-tree } & \text { 3-DEM.II } \\ \text { 'Look at that tree!' } & & \end{array}$

What is crucial in this context is that no clear perimeter is set, thus not licensing the use of series III (see also the discussion under Figure 3 and furthermore that it is naturally accompanied by a pointing gesture, which requires a referent to be spatially accessible.

4.2.2. Anaphoric use series II. Series II is the most natural demonstrative to be used in anaphoric cases. It can be used to refer to antecedents across clausal boundaries (28), and can be bound (29a) or free (29b).

$\begin{array}{llll}\text { N-á-yágííri } & \text { ó-mu-saizá n' ó-mw-aana. } \\ \text { 1SG.SM-PST-meet.PFV } & \text { AUG-1-man and } & \text { AUG-1-child } \\ \text { O-mu-saiz' óo-yo } & \text { y-á-bá-ire } & \text { mu-sanyúcí. } \\ \text { AUG-1-man 1-DEM.II } & \text { 1SM-PST-be-PFV } & \text { 1-happy } \\ \text { 'I met a man and a child. That man was happy.' }\end{array}$
Buli ó-mw-aana gw-e a-bwééne
ó-mw-aan'
óo-yo.
AUG-1-child
1-DEM.II
y-a-tumw-iiré
n'
each AUG-1-child 1-REL 1SM-see.PFV 1SM-PST-talk-PFV with
a. 'Each [child he saw $]_{\mathrm{i}}$ he talked to [that child $]_{\mathrm{i}}$.'
b. 'Each [child he saw $]_{\mathrm{i}}$ he talked to [that child] $]_{\mathrm{k}}$.' 
Often, the NP is omitted and the demonstrative is used pronominally to avoid redundancy:
Buli ó-mw-aana gw-e a-bwééne
y-a-tumw-iiré
n’ óo-yo.
each AUG-1-child 1-REL 1SM-see.PFV 1SM-PST-talk-PFV with 1-DEM.II
'Each [child he saw $]_{\mathrm{i}}$, he talked to [that one/him/her $]_{\mathrm{i} / \mathrm{k}}$.'

4.2.3. Discourse deixis series II. Series II is also the most natural series to be used in discourse deixis. This is shown in (31): in a context where our boss has just said in a speech that we need to do high-quality research, we can refer to that statement with a pronominal demonstrative in series II but not series I or III, as illustrated in (31).
Eec-o / \#Ci-no / *Ci-di
c-á
ßu-kulu
íno.
7-DEM.II 7-DEM.I 7-DEM.III
'That is very important.'

4.3. Series III. Following the same structure, the meaning of series III is defined as follows:

$\llbracket N O U N \operatorname{dem} \rrbracket=1 x[\operatorname{NOUN}(x) \& x=y]$

a. the referent of $\mathrm{y}$ is [-proximal] [+exterior]

The [+exterior] feature contributes properties that crucially differ from series II. Referents of series III need to be outside of the perimeter, which requires that a clear perimeter has been set. This can happen in at least two ways: either the perimeter can result from the presence of, and contrast with, another salient referent, or from an unchanging physical boundary (e.g. geographical). These two uses are found independently in Lugwere, as discussed in section 4.3.1.

Discourse-wise, [+exterior] means that it refers to an antecedent that is not part of the currently available discourse referents. Thus, we expect series III demonstratives to be unavailable for plain anaphoric uses, as anaphoric uses involve reference to currently salient discourse referents (cf. Roberts 2002). Instead, series III are used to refer to entities that have already been established before the current conversation but now have a reduced activation status (section 4.3.2). It is also expected that discourse deixis is impossible, since referring to a proposition or question only makes sense when the antecedent discourse entity is part of the current conversation, under the same QUD (Roberts 1996). This contradicts the requirement of the [+exterior] feature, and is thus impossible, as expected under our analysis.

In section 4.3.3, we show that the spatial [+exterior] and discourse [+exterior] features of the series III demonstrative result in an interesting pattern when one or both such referents are available. This further supports our analysis of series III demonstratives as requiring a [-proximal] but [+exterior] referent.

4.3.1. Spatial use series III. Compared to a typical three-way deictic distinction in demonstratives, we have already seen that series II can refer not just to medial but also distal elements. Series III deviates further from such a typical system. For series III to be used felicitously it is not sufficient that the referent is further away, but a clear perimeter must be established, which can be done in different ways. In (33) and the situation in Figure 1, the perimeter is established by the contrast between two referents, where the boy who is close by sets the perimeter, and by contrast with this 
referent, a series III demonstrative can refer to the referent further away - the child in colored clothes in Figure 1.
N-ták'
ó-mw-aan’ oo-dí.
1SG.SM-want AUG-1-child 1-DEM.III
'I like that child.'

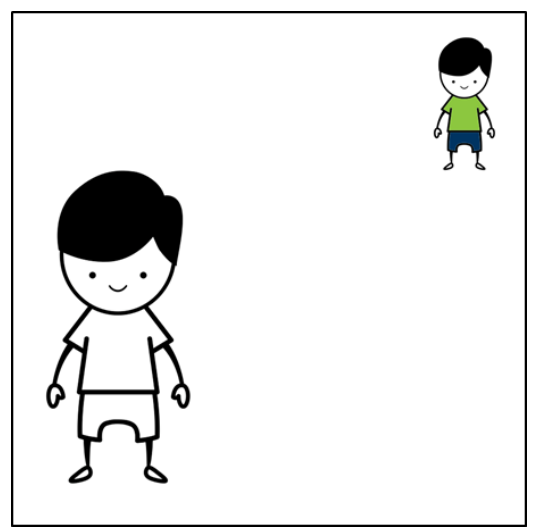

Figure 1 The target referent (in colored clothes) is further from the speaker than the other referent.

In (34) the perimeter is also set by the contrast with another referent, this time verbally mentioned rather than present in the environment. ${ }^{5}$

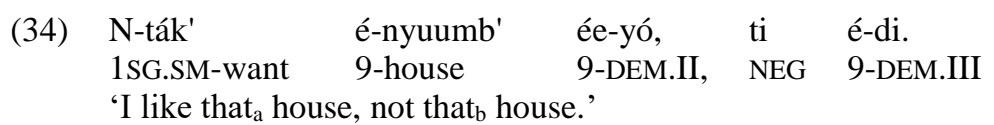

When used with a contrast with another entity, a difference in distance is not necessary. As long as the speech perimeter is focused around the other entity, reference to the intended referent is possible with a series III demonstrative. This is shown by (35) below, where we set up a contrastive context with referents that are located at the same distance from the speaker (Figure 2). If the focus of the conversation is on the boy on the left, but the speaker wants to assert that he likes the other boy (on the right, in the colored outfit), (35) can be used.

\footnotetext{
${ }^{5}$ Note that pointing is not necessary in (34), unlike with series II in a contrastive context, as in (27).
} 


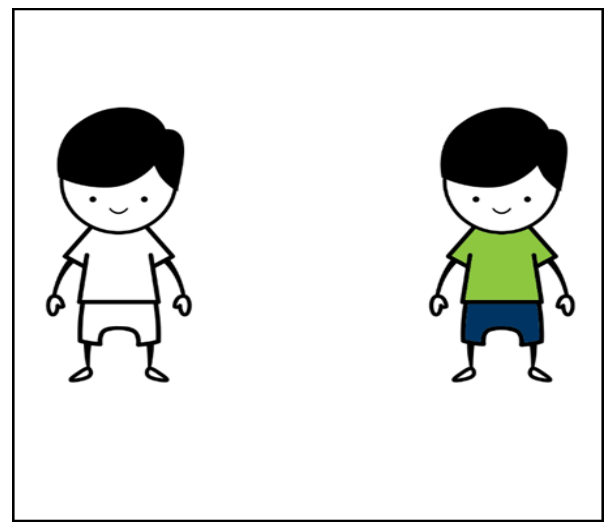

Figure 2. The two referents are equidistant from the speaker. The target referent has a colored outfit.

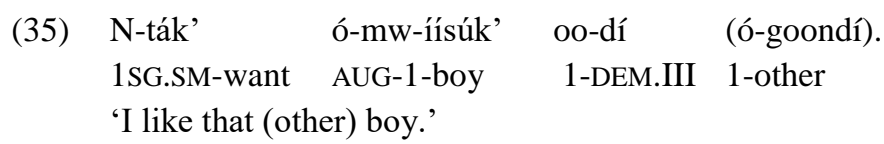

The fact that o-goondi ('other') is optional in (35) shows that the semantics of series III demonstratives inherently contains a contrastive aspect. Note that series II can be used in this same context, but $o$-goondi is required if the same kind of contrastive implication is intended.

$\begin{array}{llll}\text { (36) N-ták' } & \text { ó-mw-ísúk' } & \text { ooy-ó } & \text { \#(o-goondi). } \\ \text { 1SG.SM-want } & \text { AUG-1-boy } & \text { 1-DEM.II } & \text { 1-another } \\ \text { 'I like that other boy.' } & & \end{array}$

We suggest that this is due to the [+exterior] specification of series III: the hearer is instructed to identify a referent outside of the given perimeter, which in (35) can only refer to the other boy.

In order to test whether the perimeter can be set independent of distance, we created a context as in Figure 3 where the target referent is closer to the speaker than the contrasted referent. Even in this context, if the contrastive setting creates a perimeter between the target referent and the other referent, series III (as in (35)) can be used.

We can compare this situation to the situation in (27), where a new referent is pointed out to the hearer using series II ("look at that tree!"). Since the referent in (27) is new, we could analyze it as external to the perimeter set by discourse, and may thus expect series III to be used, contrary to fact. We suggest that the crucial difference is the presence of a clear perimeter in Figure 3 (licensing the use of series III) and its absence in (27) (requiring a [-exterior] demonstrative). When a perimeter can be specified, this may be determined by space or discourse, and the felicitous use of series III in the context of Figure 3 suggests that when spatial use and discourse use are in conflict, discourse use may be preferred. However, the interaction between space and discourse is subtle and for now we have to leave (the consequences of) this interaction for further research. 


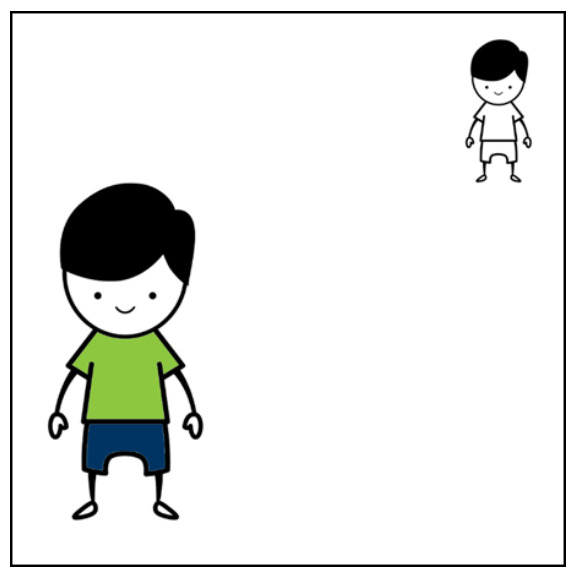

Figure 3. The target referent is closer to the speaker than the other referent.

Another way in which the required perimeter for series III can be set is if the referent is so far away from the speaker that there is an unchangeable physical boundary such as the coastline, the atmosphere of the earth, etc. In this case, a referent outside that physical boundary is predicted to be referred to with the series III demonstratives. We tested this with a hypothetical context as in Figure 4 , where there is only one tree left on earth, and we are referring to it from a different continent. By having one tree left on earth, we eliminated a potential contrast with alternatives. The fact that (37) is felicitous in this context shows that a physical boundary can also license series III, as predicted if this series is specified as [+exterior].
N-ták'
ó-mu-sáále
gu-dí.
1SG.SM-want
AUG-3-tree 3-DEM.III
'I like that tree.'

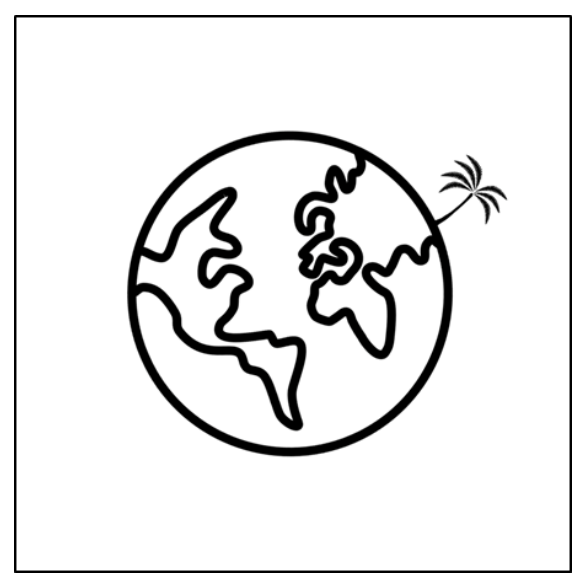

Figure 4. A unique tree located in another continent.

These tests show that series III is licensed when there is a contrast with a previously mentioned referent, and when referring to a distal non-contrastive referent. Both aspects can be captured under the feature [+exterior], where the target entity must be outside a clearly set perimeter, be that a physical boundary or one of mental attention. 
4.3.2. Series III [+exterior] discourse-wise: no endophoric uses. Endophoric uses of series III are restricted. In referring to a referent just established in the context, it is possible to use series III, but it is described as "adding much more drama": 6

$\begin{array}{llll}\text { N-á-yágííri } & \text { ó-mu-saizá n' } & \text { ó-mw-aana. } \\ \text { 1SG.SM-PST-meet.PFV } & \text { AUG-1-man } & \text { and } & \text { AUG-1-child } \\ \text { Ó-mw-aan’ ó-di } & \text { y-á-bá-ire } & & \text { mu-sanyúcí. } \\ \text { AUG-1-child } & \text { 1-DEM.III } & \text { 1SM-PST-be-PFV } & \text { 1-happy }\end{array}$

'I met a man and a child. That child was happy.'

Series III cannot have a bound reading. If we replace the series II demonstrative in the covarying example we saw in (29), with series III, then the referent in the second part of the sentence (the child) must refer to a different child that is not part of the context.

(39) Buli ó-mw-aana gw-e a-bwééne y-a-tumw-iiré n' ó-mw-aan' óo-di. each AUG-1-child 1-REL 1SM-see.PFV 1SM-PST-talk-PFV with AUG-1-child 1-DEM.III 'Each [child he saw], he talked to [that (child)] i,, $\mathrm{k}^{\prime}$ '

Discourse-deictic use is also ruled out for series III, as already shown in (31) above, and also in (40), which is unacceptable as referring to something someone said in any context.

(40) *Ci-di te-ci-sóßóká!

7-DEM.III NEG-7SM-able

'That is impossible!'

As mentioned, these restrictions are expected because anaphors refer to referents active in the mind and therefore inside the perimeter, i.e. incompatible with the [+exterior] specification of series III.

4.3.3. Combination of spatial and discourse [+exterior] referents We have shown that series III demonstratives require referents that are located outside of the perimeter, either spatially or discourse-wise. A question that arises from these observations is what would happen if both a discourse [+exterior] referent and a spatially [+exterior] referent are available, as already briefly touched upon below Figure 3. We tested all four possible combinations of discourse and spatial, and [+exterior] or [-exterior] referents and found that series III unambiguously refer to either the discourse or the spatially [+exterior] referent if there is one, but it results in ambiguity if both are available, or if neither is available.

The general context involves a sequence of two events. In the first event, two speakers are walking down the street, and they see a child (A). They talk about the child, but move on. Then follows the second event, where the two speakers run into two other children (B and C). One of the speakers points to child C (in a yellow dress) and asks the question in (41).

\footnotetext{
${ }^{6}$ We did not test whether series III in (38) can be used to refer to another child, though it is likely that reference to another child (who is outside the discourse perimeter) is possible. That series III is possible in an anaphoric context is not expected by our proposal, though the highly emphatic interpretation may suggest that this use serves another purpose (conveying evaluative expression, etc.). This needs to be tested further.
} 


$$
\begin{array}{llllll}
\text { Ó-mw-aan’ } & \text { óoy-o } & \text { mu-waanv' } & \text { óku-siinga } & \text { ó-mw-aan’ } & \text { óo-di? } \\
\text { AUG-1-child } & 1 \text { 1-DEM.II } & \text { 1-tall } & \text { 15-win } & \text { AUG-1-child } & 1 \text {-DEM.III }
\end{array}
$$

'Is that-II child taller than that-III child?'

We asked the consultant which child was being compared to the child $\mathrm{C}$, that is, who is the referent of the series III demonstrative?

The first context, shown in Figure 5, has a discourse [+exterior] referent, but no spatially [+exterior] referent: Child $\mathrm{A}$ in the first event is [+exterior] discourse-wise, and child $\mathrm{B}$ in the second event is [-exterior] both for discourse and distance. Because there was no contrast between the two girls in the second picture in the conversation, that is, there is no established boundary/perimeter, we labeled this context as having only a discourse [+exterior] referent, namely child A who was talked about in the first event. In this context, the consultant responded that the speaker is comparing child $\mathrm{C}$ to child $\mathrm{A}$ in the first picture, thus the discourse [+exterior] referent.
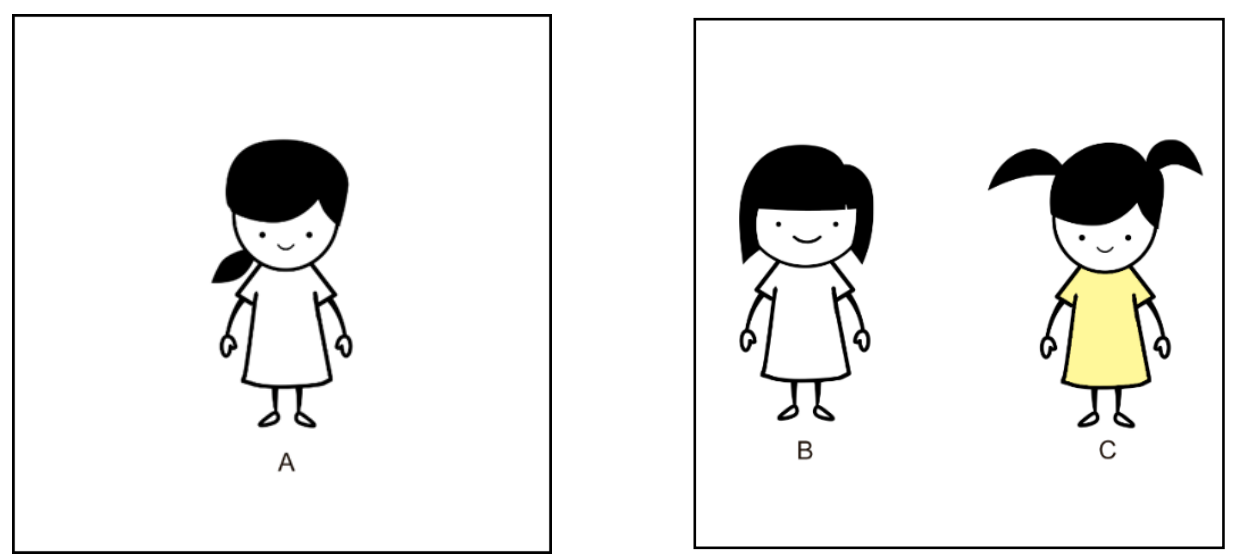

Figure 5. Context with only a discourse [+exterior] referent. First 'seeing event' is depicted to the left; second event to the right.

The second context, shown in Figure 6, differs from the first context in that the two girls in the second event are at different distances from the speaker. Thus, in this context, we have both a discourse [+exterior] referent (child A) and a spatially [+exterior] referent (child B in the back). In this context, the consultant responded that the referent is ambiguous. That is, the demonstrative in series III could refer to either child A or child B.

In the third context, we kept the same pictures as in Figure 6 but we made child A in the first picture/event [-exterior] by mentioning her in the current conversation, commenting that she was happy, as in (42), before asking the question in (41). 

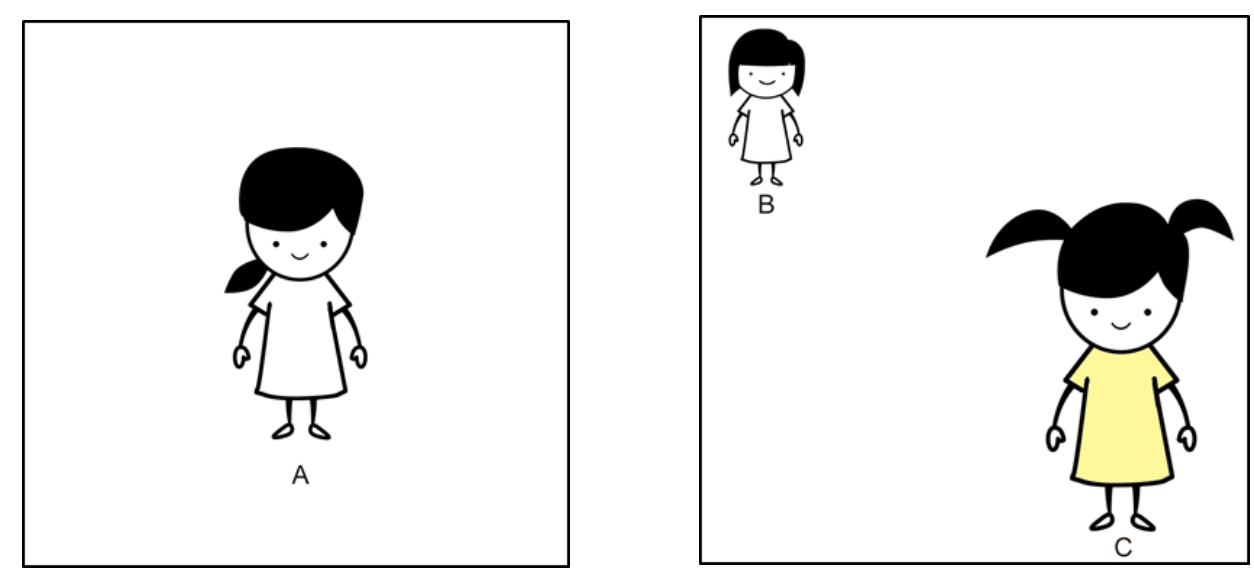

Figure 6. Context with both discourse and spatial [+exterior] referents. First 'seeing event' is depicted to the left; second event to the right.
(42) Y-á-bá-ire
mu-sanyúcí.
1SM-PST-be-PFV
1-happy
'She was happy.'

Thus, in this context, there was only a spatially [+exterior] referent, child B in the back. The consultant responded that in this case, the demonstrative refers clearly to the spatially [+exterior] child $\mathrm{B}$, not to the discourse-wise [-exterior] child A.

The fourth context had no [+exterior] referent. We presented the pictures as in Figure 5, thus eliminating the distance between the girls in the second picture/event, leaving no spatially [+exterior] referent. We also mentioned child A again as in (42), leaving no discourse [+exterior] referent either. In this context, the consultant said the reference was ambiguous. We might expect the series III demonstrative to not be appropriate at all in this context, since there is no [+exterior] referent. We have not yet followed this up.

The four contexts tested above show that series III looks for a [+exterior] antecedent, regardless of whether it is spatial or discourse. If it cannot find one unique [+exterior] antecedent, the reading is ambiguous.

In conclusion, unlike the reconstructed and still widespread use of a third series of demonstratives for exophoric distal deixis in Bantu languages, the third demonstrative series in Lugwere is better captured by a feature [+exterior], which accounts for its exophoric and endophoric reference to a referent outside a perimeter that is set in the spatial or discourse scene.

\section{Comparative aspects}

In order to see how the current demonstrative system in Lugwere may have arisen, we start by looking at the demonstrative system as reconstructed for Proto-Bantu and demonstratives in the languages surrounding Lugwere. 
We take as a point of departure the reconstructed 5-way distinction for demonstratives (Meeussen 1967): ${ }^{7}$

1. *PPx-nóo 'this near me'

2. *V-PPx 'this'

3. *V-PPx-o 'that near you/mentioned'

4. *PPx-día 'that over there'

5. *PPx 'that, the' (a weak anaphoric)

(Meeussen 1967: 107)

The majority of the Bantu languages of zone JE (following Maho 2009) all maintain a 3-way distinction in their demonstrative series, with some languages showing a 4-way distinction. Lugwere's closest Bantu neighbors Luganda (JE15), Lusoga (JE16), Nyole (JE33) and Masaba (JE31) all have a three-way distinction in demonstratives, ${ }^{8}$ with very similar forms:

\begin{tabular}{llll} 
& I & II & III \\
\hline Luganda & - no & $-o$ & - li/-ri \\
Lusoga & - no & $-o$ & - le \\
Nyole & - no & $-o$ & - la/-ra \\
Masaba & -no & $-o$ & - la/-ra
\end{tabular}

Table 3 Demonstratives in Lugwere's neighbours (Luganda: Ashton 1954, Lusoga: Steeman 2001, Nyole: Weier 1985, Masaba: Purvis 1907)

It is clear that the three demonstratives in this area are reflexes of the reconstructed forms in 1 , 3, and 4 above. Since the surrounding languages have the same three-way distinction as Lugwere, and since the current aspects of meaning found in Lugwere demonstratives are not easily recognized in the reconstructed Proto-Bantu demonstratives, it is likely that an ancestor of these languages already had a system reduced to three demonstratives. That is, the ancestor had lost the reconstructed weak anaphoric PPx, plus it conflated the -nóo and V-PPx form as a proximal demonstrative (or simply lost the latter form).

The next question is then how the semantics we established for Lugwere could have developed from this ancestor. As far as we can deduce from the descriptions, the three series of demonstratives in the languages surrounding Lugwere are distinguished according to distance and do not show the proximal/non-proximal distinction as Lugwere does. For Luganda, the first series indicate 'proximity', the second is described as 'relative proximity to the speaker' and also reference to something already mentioned (Cole 1967: 94), whereas the third series indicates 'non-proximity' (Ashton 1954: 41) or 'relative distance from the speaker' (Cole 1967: 94). Steeman (2001) describes for Lusoga demonstratives that "different aspects of distance are expressed (be they physical or mental)" where again series I is described as 'this', series II 'that, which is mentioned before', and

\footnotetext{
${ }^{7}$ Guthrie (1970) gives 12 (partially 'osculant') Comparative Series for demonstratives, covering 5 possible meanings. Dammann (1950) hypothesizes that Proto-Bantu had two demonstratives, with some languages developing a third demonstrative series for emphatic reference. Doke (1935) instead suggests two opposing pairs of demonstratives as the original system ( $=4$ 'positions', of which one or more may be lost), which Nicolle (2012) deems more plausible, considering the widespread existence of 4-way demonstrative systems. ${ }^{8}$ These languages are the closest in terms of contact, either by being spoken geographically close by, or in the case of Luganda being a language of wider communication.
} 
series III is 'that'. It may well be that these languages have more subtle semantics and uses of the demonstrative series, but the given descriptions differ from Lugwere especially in series II, which in Lugwere is non-proximal (and can refer to distal referents).

We speculate that in Lugwere the meaning of series II extended from medial to non-proximal, thus covering both the medial and distal areas. This is potentially due to the ambiguity of series I: the proximal demonstrative refers to something near the speaker, in other words it is proximal both in a person-based system and a distance-based system and thus compatible with either. Whereas 'medial' in a person-based system is clearly defined ('near the speaker'), it can be quite vague in a distance-based system (what is 'far away' and what counts as 'really far away'?). It is thus understandable how the extra distinction for distance can be lost, resulting in a two-way system proximal/non-proximal.

The reanalysis of series II as non-proximal caused an overlap with series III in the distal area, as indicated by the dotted line in Figure 7. As it is crosslinguistically common for the distal demonstrative to develop an endophoric function next to its exophoric use (Diessel 1999: 161), series III might have had a more abstract meaning already. It is then likely that the overlap that emerged with series II induced a reanalysis of series III as referring to something outside of the given domain, since that domain was now covered by series I \& II jointly. The resulting system is represented in Figure 8.

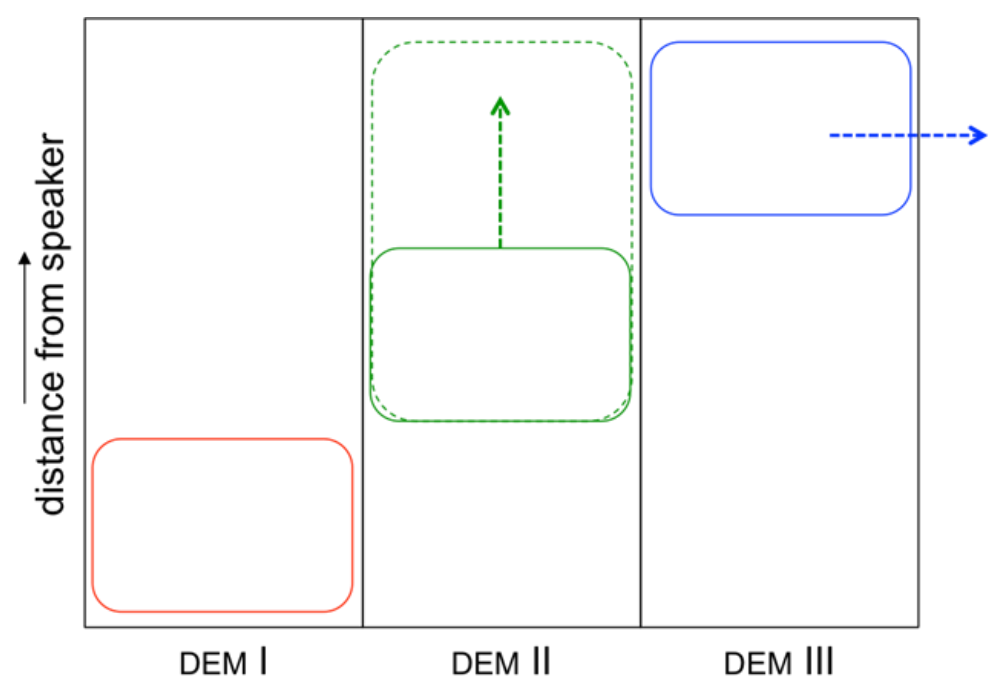

Figure 7. Earlier stage and diachronic development of Lugwere demonstrative series 


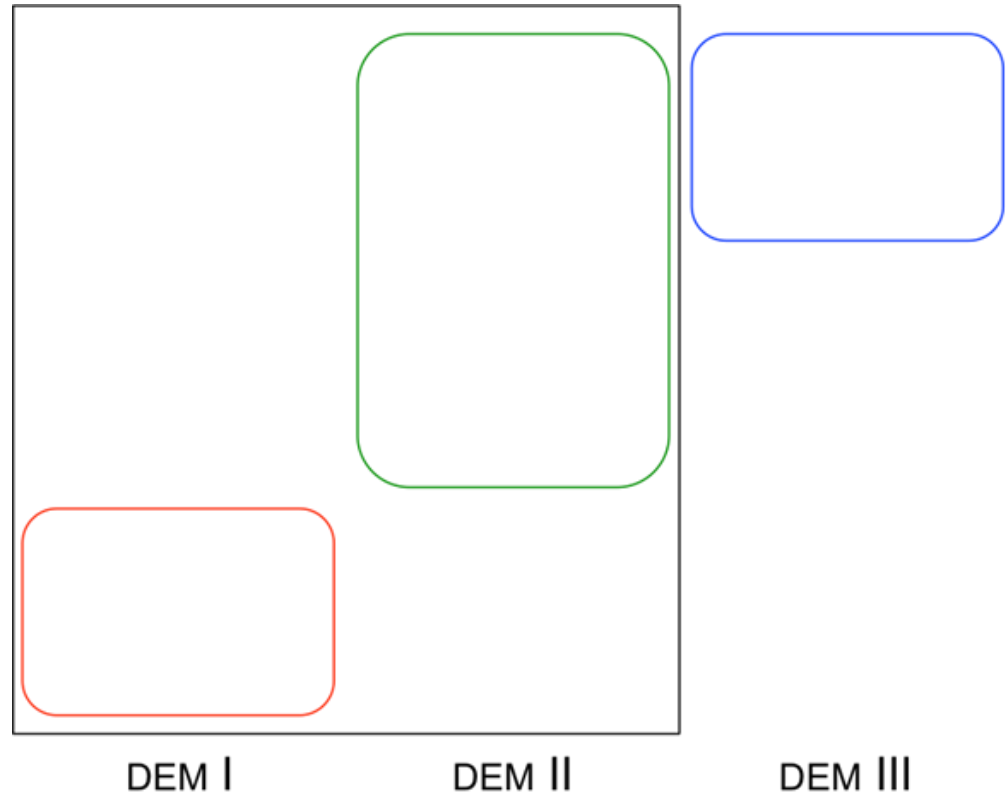

Figure 8. Current stage of Lugwere demonstrative series

The shift in meaning of series III can thus be seen as initiated by pragmatics: ${ }^{9}$ with the overlap in the non-proximal domain that resulted from the extension of series II from only medial to all nonproximal entities, the speakers may have reasoned that if series III is used, there must be a motivation for it, inferring the presence of a contrast between the entities. This associated pragmatic meaning may have over time become a semanticized core aspect of the demonstrative series' meaning. ${ }^{10}$

In terms of semantic features, the change in the three series can be characterized as a reanalysis of the feature [distal] as [exterior], where Lugwere's neighboring languages maintain the [distal] feature:

earlier stage

$\begin{array}{llll}\text { DEM I } & \text { [+proximal, -distal] } & \rightarrow & \text { [+proximal, -exterior] } \\ \text { DEM II } & \text { [-proximal, -distal] } & \rightarrow & \text { [-proximal, -exterior] } \\ \text { DEM III } & \text { [-proximal, +distal] } & \rightarrow & \text { [-proximal, +exterior] }\end{array}$

This is in line with general trends in grammaticalization, whereby words with a more concrete meaning (in this case 'spatially distal') develop a more abstract meaning (in this case 'exterior'), perhaps by metaphorical use. For the grammaticalization of demonstratives, Diessel (1999: 118)

\footnotetext{
${ }^{9}$ An alternative trigger for the change could have been the contact with neighboring Nilotic language Teso. However, this language has a three-way person-based distinction (near-speaker, near-hearer, away from both) without further effects marked (Barasa 2017:65), thus being an unlikely source of semantic change.

${ }^{10}$ A similar pragmatic reasoning is drawn upon by Meeuwis \& Stroeken (2010) to explain the difference in interpretation between Lingala non-proximal demonstratives yangó (referential continuity) vs. wâná (discontinuity, some effort must be made to establish which referent is intended). While the pragmatic influence may be similar, we do not believe that the Lingala demonstratives can similarly be analyzed with reference to exteriority.
} 
suggests that functionally, demonstratives develop gradually to point less and less to entities in the outside world, and become deictically less and eventually no longer contrastive (Diessel 1999: 181). With respect to these criteria, it is interesting to note that both series II and III in Lugwere can refer exophorically and endophorically, and the endophoric use of series II and III is still deictically contrastive, with respect to the perimeter. This indicates that if series III has started on Diessel's proposed path of grammaticalization, it has not developed very far yet.

A remaining question is whether other languages of the world have similar developments of this exterior demonstrative. A promising case is Korean, which has a three-way distinction in demonstratives $(i, c e, k u)$. Unlike the proximal $i$ and distal $c e$ which are exophoric, $k u$ only allows anaphoric uses (cf. Ahn 2017; Cho 2017). The semantics of the three demonstratives ce, $i$, and $k u$ may also be captured by the features [proximal] and [exterior], where the [-proximal, +exterior] $k u$ has continued the development from spatial reference (to entities outside the perimeter thus invisible) to an (exclusively) anaphoric function (to entities that are familiar).

\section{Conclusions}

We have proposed an analysis of the three series of Lugwere demonstratives in terms of the two semantic features [proximal] and [exterior], indicating respectively proximity to the speaker and exteriority with respect to a perimeter in both domains of space and discourse:

\begin{tabular}{|l|l|l|}
\hline & {$[+$ exterior $]$} & {$[$-exterior $]$} \\
\hline$[+$ proximal $]$ & $($ logically impossible $)$ & I \\
\hline$[$-proximal $]$ & III & II \\
\hline
\end{tabular}

Our analysis for Lugwere suggests that the more abstract notion of exteriority with respect to a perimeter provides a better insight into the semantics of the demonstrative system of Lugwere and potentially other languages, going beyond the familiar thinking in terms of space and anaphoricity. This proposal for the semantics should however be tested further in longer stretches of spontaneous language use, which will doubtlessly also uncover further pragmatic functions of demonstratives (cf. Himmelmann 1996; Meeuwis \& Stroeken 2010; Van der Wal 2010; Nicolle 2014).

Many questions remain, for Lugwere as well as in general: What is the function and the meaning of the order variation between noun and demonstrative in Lugwere (cf. Van de Velde 2005; for Swahili Wilt 1987; Carstens 1991; Mwamzandi 2014), and can this be captured in another semantic feature or does the difference lie in the pragmatics? How does the proposed analysis for Lugwere compare to typologically different systems (e.g. Korean, Romanian, etc.)? Can the feature exteriority be broken down into smaller semantic building blocks? We leave these questions for further research but hope that this paper will contribute to a better understanding of the semantics of Lugwere demonstratives and demonstratives in general. 


\section{Abbreviations and symbols}

Numbers refer to noun classes, or to persons when followed by SG or PL. High tones are marked by an acute accent, low tones are unmarked or marked by a grave accent. Roman numerals refer to series of demonstratives.

$\begin{array}{ll}\text { APPL } & \text { applicative } \\ \text { AUG } & \text { augment } \\ \text { CONN } & \text { connective } \\ \text { DEM } & \text { demonstrative } \\ \text { INT } & \text { intensifier } \\ \text { NPx } & \text { nominal prefix } \\ \text { OM } & \text { object marker } \\ \text { OPT } & \text { optative } \\ \text { PFV } & \text { perfective } \\ \text { PPx } & \text { pronominal prefix } \\ \text { PST } & \text { past tense } \\ \text { SM } & \text { subject marker } \\ \text { V } & \text { vowel }\end{array}$

\section{References}

Ahn, Dorothy. 2017. Semantics of definite description: A micro-typology. GLOW 2017 Presentation.

Ashton, Ethel O., Enoch E.K. Mulira, E.G.M. Ndawula \& Archibald N. Tucker. 1954. A Luganda grammar London: Longmans, Green and Co.

Barasa, David. 2017. Ateso grammar. A descriptive account of an Eastern Nilotic language. München: LINCOM.

Burenhult, Nicolas, 2008. Streams of words: Hydrological lexicon in Jahai. Language Sciences, 30(2), pp.182-199.

Carstens, Vicki. 1991. The morphology and syntax of determiner phrases in Kiswahili. Los Angeles, CA: UCLA dissertation.

Chang, Soo Jung. 2009. Nominal structure and interpretation: On the syntax of the Korean Determiner Phrase. Athens, GA: University of Georgia dissertation.

Cho, Jacee. 2017. The acquisition of different types of definite noun phrases in L2English. International Journal of Bilingualism 21(3): 367-382.

Cole, Desmond. 1967. Some features of Ganda linguistic structure. Johannesburg: Witwatersrand University Press.

Dammann, Ernst. 1950. Das Demonstrativ in Bantu-sprachen. Zeitschrift der Deutschen Morgenländischen Gesellschaft 100: 638-645.

Davis, Christopher \& Christopher Potts. 2010. Affective demonstratives and the division of pragmatic labor. Logic, Language and Meaning, 42-52.

Diessel, Holger. 1999. Demonstratives: form, function, and grammaticalization. Amsterdam: John Benjamins.

Doke, Clement M. 1935. Bantu linguistic terminology. London: Longmans, Green and Co.

Guthrie, Malcolm. 1970. Comparative Bantu, 4 volumes. Farnborough: Gregg International.

Heim, Irene. 1982, The Semantics of Definite and Indefinite Noun Phrases. Amherst, MA: University of Massachusetts dissertation. 
Heim, Irene. 1983, File Change Semantics and the Familiarity Theory of Definiteness, in R. Bäduerle, Ch. Schwarze \& A. yon Stechow (eds.), Meaning, Use and Interpretation of Language, 164-189.

Heim, Irene. 1990. E-type pronouns and donkey anaphora. Linguistics and philosophy, 13(2): 137177.

Himmelmann, Nikolaus P. 1996. Demonstratives in narrative discourse: A taxonomy of universal uses. In Barbara Fox (ed.), Studies in anaphora, 205-254. Amsterdam: John Benjamins.

Kamp, Hans. 1981. A theory of truth and semantic representation. In Paul Portner \& Barbara H. Partee (eds.) Formal Semantics - the Essential Readings, 189-222. Blackwell.

Maho, Jouni. 2009. NUGL online: the online version of the New Updated Guthrie List, a referential classification of the Bantu languages. Available online at glocalnet.net/ mahopapers/nuglonline.pdf

Meeussen, Achille E. 1967 Bantu grammatical reconstructions. Africana Linguistica 3: 79-121.

Meeuwis, Michael \& Koen Stroeken. 2010. Non-situational functions of demonstrative noun phrases in Lingala (Bantu). Pragmatics 22(1):147-166.

Meira, Sérgio. 2003. 'Addressee effects' in demonstrative systems. The cases of Tiriyó and Brazilian Portuguese. In Friedrich Lenz (ed.), Deictic conceptualization of space, time, and person, 3-12. Amsterdam: John Benjamins.

Mwamzandi, Mohamed Yusuf. 2014. Word order choices: insights from information structure. Arlington, TX: The University of Texas at Arlington dissertation.

Nicolle, Steve. 2012. Semantic-pragmatic change in Bantu -no demonstrative forms. Africana Linguistica 18: 193-233.

Nicolle, Steve. 2014. Discourse functions of demonstratives in Eastern Bantu narrative texts. Studies in African Linguistics 43(2): 125-144.

Potts, Christopher \& Florian Schwarz. 2010. Affective 'this'. Linguistic Issues in Language Technology 3(5): 1-30.

Roberts, Craige. 1996. Information structure in discourse: Towards an integrated formal theory of pragmatics. OSU Working Papers in Linguistics 49. 91-136.

Roberts, Craige. 2002. Demonstratives as definites. In Kees van Deemter \& Rodger Kibble (eds.), Information sharing: Reference and presupposition in language generation and interpretation, 89-196. CLSI: Stanford.

Simons, Gary F. \& Charles D. Fennig (eds.). 2017. Ethnologue: Languages of the World, Twentieth edition. Dallas, Texas: SIL International. Online version: http://www.ethnologue.com.

Sohn, Ho-min. 1994. Korean. Descriptive Grammars. London/New York: Routledge.

Steeman, Sander. 2002. Kintu, an annotated Lusoga play. Leiden, Netherlands: Leiden University MA thesis.

Meira, Sérgio \& Angela Terrill. 2005. Contrasting contrastive demonstratives in Tiriyó and Lavukaleve . Linguistics. 43(6): 1131-1152.

Van de Velde, Mark. 2005. The order of noun and demonstrative in Bantu. In Koen Bostoen \& Jacky Maniacky (eds.), Studies in African comparative linguistics: with a focus on Bantu and Mande, 425-442. Tervuren: RMCA.

Van der Wal, Jenneke. 2010. Functions of demonstratives in Makhuwa narratives. Africana Linguistica XVI: 183-213.

Weier, Hans-Ingolf. 1985. Basisdemonstrativa im Bantu. Hamburg: Helmut Buske.

Wilkins, David P. 1989. Mparntwe Arrernte (Aranda): Studies in the structure and semantics of grammar. Canberra, Australia: Australian National University dissertation.

Wilt, Timothy. 1987. Discourse distances and the Swahili demonstratives. Studies in African Linguistics 18(1), 81-95. 
Ahn, Dorothy <dorothyahn@g.harvard.edu>

Department of Linguistics

Harvard University

Cambridge.

Jenneke van der Wal <g.j.van.der.wal@hum.leidenuniv.nl>

Leiden University Centre for Linguistics

Leiden.

The Netherlands. 